\title{
HISTORIA DE LA LENGUA. HISTORIA DE LA CIENCIA LITERARIA (DOS ANÁLISIS BIBLIOGRÁFICOS)
}

FRANCISCO ABAD NEBoT

UNED

A sugerencia de varios compañeros complementamos nuestra anterior «Muestra de una bibliografía comentada de Historia de la lengua española» (EPOS, VII, 1991); valen las mismas advertencias iniciales que entonces hicimos. En segundo término nos ocupamos de fuentes y bibliografía para la Historia de las ideas literarias en España.

- Alonso, Amado, Castellano, español, idioma nacional, Buenos Aires, Instituto de Filología, 1938.

Un tratamiento clásico y el único de conjunto que poseemos acerca de la cuestión del nombre del idioma. En síntesis mantiene Amado cómo «castellano y español nombran a un mismo objeto con perspectivas diferentes. $Y$ aun en el correr de la historia, la visión subjetiva que corresponde a cada nombre ha ido cambiando».

Trabajo imprescindible, aunque hoy se tenga mayor documentación que debería sistematizarse. 
- Alonso, Amado, Estudios lingüísticos. Temas hispanoamericanos, Madrid, Gredos, $1967^{3}$.

Tomo de escritos en los que se exponen la doctrina personal del autor acerca de la base linguística del español americano, y asimismo cuestiones de geografía fonética española y americana, y acerca de la forma interior del lenguaje en Hispanoamérica.

- Alvar, Manuel, Niveles socio-culturales en el habla de Las Palmas de Gran Canaria, Las Palmas, Cabildo Insular, 1972.

Estamos ante el análisis diastrático de la fonética de una de las hablas urbanas del mundo hispánico, más páginas finales de comentario teórico en tomo al problema «lengua y sociedad». El asunto lo ha replanteado de manera distinta Manuel Almeida, El habla de Las Palmas de Gran Canaria, Centro de la Cultura Popular Canaria, Santa Cruz de Tenerife, 1990.

- Alvar, Manuel, Leticia, Bogotá, Caro y Cuervo, 1977.

Volumen sobre cuestiones suscitadas en la Amazonia colombiana: fonética y fonología, lenguas en contacto, actitudes lingüísticas, etc.

- Alvar, Manuel, La lengua como libertad, Madrid, Cultura Hispánica, 1982.

Reunión de artículos algunos de ellos referidos a los conceptos de «norma» y de «dialecto». La argumentación la ha mantenido y prolongado luego el autor en «¿Existe el dialecto andaluz?», NRFH, XXXVI, 1988, pp. 9-22.

- Badía MARGarit, A., «Ensayo de una sintaxis histórica de tiempos. El pretérito imperfecto de indicativo», BRAE, XXVIII, 1948, pp. 281-300 y 393410; XXIX, 1949, pp. 15-29.

«El presente estudio - manifiesta Badía - aspira a remontar a través de la historia de la lengua, cada uno de los valores que le han sido atribuídos» [al pretérito imperfecto]. Se trata en efecto de un inventario de los usos del tiempo, y de la reseña histórica de tales usos. 
Trabajo necesario, como necesarios son otros análogos para las demás formas del verbo.

- CARMONA, Fernando y FLORES, Francisco J., eds., La lengua y la literatura en tiempos de Alfonso X, Universidad de Murcia, 1985.

Reunión de ponencias y comunicaciones algunas de ellas - no muchasreferidas a los problemas lingüísticos de la obra alfonsí, y en las que se tiene en cuenta la tantas veces olvidada General Estoria. Por razones quizá de distribución, el volumen parece haber pasado prácticamente desapercibido.

- Catalán Mz. Pidal, Diego, De Alfonso X al Conde de Barcelos, Madrid, Gredos, 1962.

Aunque este libro está dedicado a «la rama más viva de la cultura medieval, la historiografía en lengua romance», importa asimismo al estudioso de la prosa y la lengua y estilo medievales.

- Catalán, Diego, Lingüística Íbero-románica, Madrid, Gredos, 1974.

Crónica de «cien años de lingüística hispano-románica», hecha con información difícilmente allegable por una persona sola (de ahí el mérito del esfuerzo), y con claridad de ideas interpretativa. Muy útil y orientadora.

- CoRominas, Joan, Tópica Hespérica, Madrid, Gredos, 1972.

Reunión de más de veinte estudios sobre los antiguos dialectos -como dice el autor en su subtítulo-, el substrato y la toponimia romances. De manejo imprescindible, para lo que pueden ayudar en ocasiones sus dos índices de «Gramática, afijos y conceptos», y de «Palabras y nombres propios».

\section{- Enciclopedia Lingüística Hispánica, II/1, Madrid, CSIC, MCMLXVII.}

Se abordan en útiles síntesis los elementos constitutivos léxicos del español, sin que se trate de los anglicismos. Asimismo quedan enumeradas las fuentes (literarias, históricas, jurídicas) para el estudio de la historia de la lengua, 
echándose ahora de menos una referencia a los gramáticos, lexicógrafos, etc., en cuanto testimonio de valor documental.

- FERnández Ramfrez, Salvador, Gramática Española, segunda ed., Madrid, Arco/Libros, 1985 ss.

«Excepcional» (R. Lapesa). Por el alcance de sus distinciones analíticas esta obra verdaderamente maestra quedará siempre como un modelo y un ejemplo; dada su atención a los caracteres de todo el español contemporáneo y sus alusiones a otras épocas del idioma, resulta ineludible en un estudio histórico de la lengua.

- García Blanco, Manuel, La lengua española en la época de Carlos V, Madrid, Escelicer, 1967.

Reunión - bajo el título del primero de ellos- de escritos lexicográficos y onomásticos de su autor, y de tres acerca de historia de la lengua. El estilo filológico, histórico y cultural de la escuela pidalina se ve bien en estas páginas de un discípulo (en parte) de don Ramón y un «sabio hombre de letras», según le llama Lapesa en el prólogo al volumen.

- Gilman, Stephen, Tiempo y formas temporales en el «Poema del Cid», Madrid, Gredos, 1961.

Recuentos detallados de formas y usos, más razonamiento acerca de la voluntad expresiva y de estilo que alienta en tales usos de las formas.

- GonZález Muela, Joaquín, El lenguaje poético de la generación GuillénLorca, Madrid, Insula, 1955.

Trabajo bello e instructivo y que representa tempranamente una clase de análisis luego muy postulada. Atiende tanto al nombre y al verbo como a las formulaciones oracionales. 
- Guitarte, Guillermo L., Siete estudios sobre el español de América, México, UNAM, 1983.

Reunión de siete escritos en torno a la historia del español de América, en el tono general de alta calidad y muy rigurosa documentación que distinguen a su autor.

- GuTIÉRREz CuADRADo, Juan, «Darwin en la linguística española del siglo XIX», en las Actas del II Congreso de la SEHCYT, Zaragoza, 1984, I, pp. 429-448.

Una de las sugestivas aportaciones que este catedrático de Historia de la lengua española viene haciendo a la historiografía de nuestras ideas lingüísticas; el prof. Gutiérrez Cuadrado se ocupa en general de aspectos bastante poco conocidos de los estudios sobre el lenguaje de los siglos XVIII y XIX.

- IORDAN, Iorgu, Lingüística románica, trad. esp., Madrid, Alcalá, 1967.

El autor considera que «nuestra disciplina... se caracteriza por una actividad rica y variada», y que entre sus más importantes realizaciones «hay que contar la geografía lingüística y la estilística»; en efecto una y otra materia quedan reseñadas con detalle.

En su primera versión el texto lo comentó Ángel Rosemblat: $R F H$, II, 1940, pp. 182-183.

- LAPESA, Rafael, Formación e Historia de la lengua española, Madrid, Enrique Prieto, 1943.

Hemos podido adquirir en librería de viejo este precioso manual que contiene un capítulo previo de «Ideas generales sobre el lenguaje y su evolución», una Historia abreviada de la lengua española, y una «Gramática histórica» del idioma: fonética, partes de la oración, y formación de palabras. Se trata del único texto en que nuestro autor ha expuesto de manera ordenada y completa la «gramática histórica» castellana, y lo ha hecho con notoria precisión y claridad. 
- LAPESA, Rafael, Estudios de historia lingüística española, Madrid, Paraninfo, 1985 .

Tomo muy denso y monográfico en torno a «dos de las grandes crisis experimentadas por la comunidad hispánica y su lengua: la que en los siglos XI a XIII decidió la incorporación de España al mundo europeo conservando su peculiaridad, y la que dio personalidad al vivir y hablar andaluces y los proyectó en la deslumbrante expansión atlántica». Es el libro de un maestro inigualado en alguna de sus calidades.

- LAPESA, Rafael, De la Edad Media a nuestros dias, Madrid, Gredos, 1967.

Reunión de diecinueve artículos fundamentalmente de historia literaria, pero que también analizan la lengua de los cantares de gesta, la del romancero viejo, la del Auto de los Reyes Magos, la de Feijoo, etc. Escritos de tono clásico, en la tradición de sensibilidad filológica, literaria y estilística de la «escuela española».

- LAPESA, Rafael, «Un, una como artículo indefinido en español», recogido en «Dos estudios sobre la actualización del sustantivo en español», Boletín de la Comisión permanente [de la Asociación de Academias], 21, 1975, pp. 3-13.

Independientemente de su valor específico, este trabajo ilustra bien cómo la consideración sincrónica y la diacrónica pueden conjugarse y deben hacerlo al argumentar en sintaxis. El autor hace una historia en abreviatura de un y una como artículos, y señala ya desde los textos antiguos su empleo en tanto «introductores de lo que representa novedad en el discurso y de lo que se menciona con realce ponderativo o con intensa expresividad».

- LAPESA, Rafael, «La huella de Américo Castro en los estudios de lingüística española», en Américo Castro: The Impact of His Thought, Madison, 1988, pp. 97-113.

Recorrido por el trabajo lingüístico técnico de don Américo, tanto durante su profesorado en la Universidad de Madrid como luego en el cuarto de siglo 
posterior a 1948. Se trata de la primera vez que se analiza este lado de la obra del maestro granadino, lo que se hace en páginas inestimables por su valor testimonial.

- LOPE BlaNCH, Juan M., Análisis gramatical del discurso, México, UNAM, 1983.

"He tratado de estudiar en sus rasgos fundamentales -dice Lope- las estructuras básicas del discurso en lengua española, atendiendo tanto a su modalidad literaria... cuanto a su realización oral —en sus niveles popular y culto". Ejemplos en efecto medievales y del Siglo de Oro, del habla urbana culta contemporánea, etc.

- LOPE BLANCH, Juan M., Estudios de lingüística española, México, UNAM, 1986.

Artículos de sintaxis histórica, sobre el habla culta de Madrid, y dos contribuciones iniciales sobre el nombre del idioma, y acerca de «el concepto de prestigio y la norma lingüística del español».

- MondéJAR, José, El verbo andaluz, Madrid, CSIC, 1970.

Tesis doctoral que ordena y analiza los materiales oportunos que se encuentran en los cuestionarios del $A L E A$. "La tesis central del libro es el polimorfismo... del sistema verbal andaluz» (Adolf Sawoff).

- Morillo-Velarde, Ramón, «Dialectología, Sociolingüística y Ecología dialectal», Glosa, 2, 1991, pp. 445-454.

El autor razona la idea de que «la Dialectología hay que entenderla como una parte de la Historia de la lengua», y diseña cómo «una perspectiva ecológica del lenguaje» debe tratar de la identificación de los usuarios del idioma, de las variedades concurrentes de habla y las actitudes lingüísticas, etc. Si se nos permite decirlo, apuntaremos la satisfacción intelectual que nos ha traído en- 
contrar en un catedrático específico de «Dialectología» posturas que nosotros hemos mantenido desde hace ya bastante tiempo.

- RIDRUEJo, Emilio, Las estructuras gramaticales desde el punto de vista histórico, Madrid, Síntesis, 1989.

Ejemplificación de los procesos que actúan en la diacronía idiomática; compleméntese con el artículo anterior «El cambio sintáctico a la luz del funcionalismo coseriano", Das sprachtheoretische Denken Eugenio Coserius in der Diskussion, Tübingen, Gunter Narr, 1987, pp. 121-133.

- RONA, José Pedro, Algunos aspectos metodológicos de la dialectología hispanoamericana, Montevideo, 1958.

Trabajo seminal —se haya dicho explícitamente en todas las ocasiones o no- para los ulteriores estudios dialectales hispánicos.

- Tovar, Antonio, Lo que sabemos de la lucha de lenguas en la Península Ibérica, Madrid, Gregorio del Toro, 1968.

Presentación, en tono de ensayo y accesible pero con rigurosidad, de los dominios lingüísticos peninsulares y de su historia.

II

\section{A) Algunas fuentes para la historia de la ciencia literaria española}

- Santillana, Marqués de, Prohemio e carta, ed. de Ángel Gómez Moreno en «El Prohemio e carta del Marqués de Santillana y la teoría literaria del s. XV», Barcelona, PPU, 1990.

Excelente trabajo muy laboriosamente erudito, y que sería deseable tener para otros textos de doctrina poética. 
- EnZina, Juan del, Arte de poesía castellana, ed. de Francisco López Estrada en "Las poéticas castellanas de la Edad Media», Madrid, Taurus, 1984.

Texto más una primera anotación de un escrito de relieve para entender - por ejemplo- la historia de la métrica española, y que debe estudiarse junto a lo dicho anteriormente por Nebrija en su Gramática. Una renovada visión del encabalgamiento (más acorde acaso con los hechos que otras que se han propuesto) que tiene presente lo dicho por Encina, puede verse en R. Senabre «El encabalgamiento en la poesía de Fray Luis de León», RFE, LXII, 1982, pp. 39-49.

- Herrera, Fernando de, Anotaciones a las Obras de Garci Lasso, ed. de Antonio Gallego Morell en «Garcilaso de la Vega y sus comentaristas», Madrid, Gredos, $1972^{2}$.

Texto fundamental para ilustrar por ejemplo la revolución poética garcilasiana, y que importa asimismo en la historia de las ideas lingüísticas en España. Desde el punto de vista de la estética ha glosado algunos pasajes en varios de sus trabajos el prof. Emilio Orozco.

- López Pinciano, Alonso, Philosophia Antigua Poetica, ed. de Alfredo Carballo Picazo, Madrid, CSIC, 1953.

El prof. Carballo prestó un extraordinario servicio sacando al mercado por vez única en nuestro siglo esta obra de importante impronta en Cervantes, y que «constituye la más alta creación de la estética literaria española en el siglo XVI» según ha expresado Antonio Vilanova. El Pinciano advertía entre muchas otras cosas «el ruydo y sonido» del arte mayor castellano, y asimismo se ocupo «del poético lenguaje».

- Vega, Lope de, Arte Nvevo, ed. de Juana de José Prades, Madrid, CSIC, 1971.

El más extenso comentario que poseemos del texto lopeveguesco, debido a una estudiosa que se ocupó tempranamente de la teoría literaria tanto en su tesis doctoral como en otras contribuciones. De manejo necesario. 
- Orozco Díaz, Emilio, En torno a las «Soledades» de Góngora, Universidad de Granada, MCMLXIX.

Edición y comentario de textos inéditos que han venido a precisar concretamente la historia de la polémica de las Soledades. Libro a veces desconocido por estudiosos que debieran conocerlo, en algún caso ha sido seguido sin que quede la obligada mención del mismo.

- Cascales, Francisco, Cartas Filológicas, ed. de Justo García Soriano, Madrid, Clásicos Castellanos, varias eds.

Contiene entre otros textos que importan la «Epístola al licenciado Luis Tribaldo de Toledo» en la que se proclama cómo «la obscuridad del Polifemo no tiene excusa», ya que «no nace de recóndita doctrina» sino del orden de las palabras y la metáfora acumulada. Como ha subrayado la crítica «cartas filológicas» quiere decir «cartas eruditas».

- JÁUREGUI, Juan de, Antídoto contra la pestilente poesía de las «Soledades», en Eunice Joiner Gates, ed., «Documentos gongorinos», El Colegio de México, 1960.

Texto en el que asimismo se mantiene que si el poeta tratase «pensamientos exquisitos i sentencias profundas, sería tolerable... la obscuridad».

- DíaZ DE RIBAS, Pedro, Discursos apologéticos, ibid.

También Eunice Joiner Gates ha publicado este texto inédito hasta entonces, en el que por contra se concluye que «lo que llaman obscuridad en nuestro Poeta no es falta suya, sino sobra de virtudes poéticas y falta... en el lector».

- JÁuregui, Juan de, Discurso poético, ed. de Melchora Romanos, Madrid, Editora Nacional, 1978.

Excelente trabajo de una estudiosa concienzuda de la materia. En su «Discurso» Jáuregui distingue -como se sabe- la oscuridad en las palabras de una «segunda oscuridad o bien la llamemos dificultad». 
- VelaZQUEZ, Luis Josef, Orígenes de la poesía castellana, Málaga, Herederos de D. Francisco Martinez de Aguilar, $1797^{2}$.

Este texto aparecido por ver primera en 1754 importa en la historia de la historiografía literaria española, y se inscribe en el esfuerzo historiográfico del Setecientos que analizó por ejemplo José Antonio Maravall en un artículo suyo de Revista de Occidente, número 107 (1972).

- Mayans y SisCaR, Gregorio, O.C., III: «Retórica», ed. de Antonio Maestre, Ayuntamiento de Oliva, 1984.

Cuidada edición del texto de uno de los autores absolutamente relevantes de la primera Ilustración española. Hoy día se ha rectificado mucho la calificación y la estimación de Mayans, lo que ha llevado a un análisis de XVIII más empíricamente adecuado.

- SARMIENTo, Fr. Martin, Memorias para la historia de la poesia, y poetas españoles, Madrid, Joachin Ibarra, MDCCLXXV.

Escrito que por igual ha de tenerse presente en el desarrollo de la historiografía literaria española, y que también trata de la «lengua vulgar» de los españoles.

- CaPmany, Antonio de, Filosofía de la eloquencia, Madrid, Sancha, MDCCXXVII.

Según resulta mejor conocida se agiganta la figura de Capmany en la historia intelectual toda del Setecientos; por supuesto hay que atender también a su tratado retórico, que apareció de nuevo en Londres en 1812, en «nueva edición -escribe el autor- nueva en todo menos en el título». No obstante es indudable una cierta unicidad entre ellas.

Capmany trata fundamentalmente de la «elocución oratoria», y en 1812 abordó asimismo la «pronunciación» y la «acción». El criterio último de don Antonio está considerado como más purista que el de sus publicaciones anteriores. 
- ANDRÉs, Juan, Origen, progresos y estado actual de toda la literatura, Madrid, Sancha, MDCCLXXXIV y ss.

Traducción castellana del original italiano, esta obra enciclopédica y monumental contiene capítulos - por ejemplo el XI del tomo II- que han podido servir de sugerencia a los investigadores más modernos. En otro de los tomos aparece un Libro que trata «De la gramática», creemos que no tenido en cuenta hasta ahora.

- García Luna, Tomás, Lecciones de filosofía ecléctica, Madrid, I. Boix, 1843.

Hacia el final del tomo primero y en las lecciones iniciales del segundo están las páginas que nos impoprtan desde el punto de vista de las ideas estéticas. La obra en su total es muy representativa de un momento de la cultura española.

- GINER, Francisco, Estudios de literatura y arte, Madrid, V. Suárez, $1876^{2}$.

Obra igualmente muy representativa de una dirección posterior de la cultura española, y con duradera trascendencia que Ilega acaso hasta algunas concepciones de Antonio Machado y Menéndez Pidal. De lectura imprescindible.

- CRIADO DE VAL, Manuel, Atlántico. Ensayo de una breve estilística marina, Madrid, s.a. [1944].

Mencionamos esta olvidada obra ya de nuestro siglo porque en ella se habla tempranamente de la crisis del positivismo, la aparición de la estilística en cuanto «orientación estética» que se da al estudio de la filología, etc. El autor subraya «lo mismo las investigaciones que buscan en el lenguaje la expresión del carácter, como las que se interesan por la expresión afectiva o estética».

Estamos ante un testimonio que debe ser tenido en cuenta. 
- ASENSIO, Eugenio, Poética y realidad en el cancionero peninsular de la Edad Media, Madrid, Gredos, 1957.

La primera obra española - creemos- que se hace eco del formalismo ruso; merced a su magnífico conocimiento de lenguas, Asensio traduce directamente a Shklovski, incorpora a Jakobson, y analiza «la poética del paralelismo».

Volumen muy bello.

\section{B) Bibliografia}

- Garcfa BERRIO, Antonio, Formación de la Teoría literaria moderna. Teoría poética del Siglo de Oro, Universidad de Murcia, 1980.

Extenso ensayo planteado de manera convergente en parte con el que citamos luego de Luis C. Pérez y Federico Sánchez Escribano: se analizan en efecto también los problemas poéticos de ingenio y arte, entretener y deleitar, pintura y poesía (en páginas publicadas separadamente como artículo), etc.; estamos pues ante la identificación en los textos de la huella horaciana.

En cuanto a periodización nuestro autor se decide a distinguir entre el «Medievo» y el «Romanticismo o quizás incluso... los albores de nuestro siglo», una sola «Edad Renacentista».

- José Juana de, La Teoría Literaria, Madrid, Instituto de Estudios Madrileños, 1954.

Monografía bibliográfica de una estudiosa - como queda dicho- preocupada siempre por la preceptiva literaria; registra ahora las Retóricas, Poéticas, etc., desde mitad del XVI en referencias hechas con toda honradez y escrúpulo profesional. No se trata de una enumeración totalmente exhaustiva, pero sí muy útil.

- MARTI, Antonio, La preceptiva retórica española en el Siglo de Oro, Madrid, Gredos, 1972.

Panorama completo de la retórica española renacentista y barroca, más enjuiciamiento histórico y crítico de la misma. Obra indispensable. 
- Orozco DfAZ, Emilio, Temas del Barroco de poesía y pintura, Universidad de Granada, 1947.

Uno de los mejores libros de su autor, con ideas fundamentales plenamente vigentes y planteamiento riguroso que demuestra un tan amplio conocimiento de la literatura como de la Historia del arte. Es obra que en su día fue recibida muy favorablemente por reseñistas de excepción: Ángel Álvarez de Miranda, Enrique Lafuente Ferrari, José Antonio Maravall...

- OROzco Díaz, Emilio, Introducción al Barroco, Universidad de Granada, 1988.

Reunión póstuma en dos volúmenes - a cargo de José Lara- de muchos estudios que es necesario ver: el autor hace una amplia «Introducción al Barroco literario español», aporta materiales para la historia de la propia palabra barroco, analiza desde el punto de vista de la preceptiva retórica el Arte nuevo de Lope, etc.

En cuanto a cronología Orozco insiste en «la necesidad de admitir una periodización que fragmenta el macroperíodo renacentista»; en efecto Renacimiento y Barroco parecen constituir dos fases A y B de lo histórico, con continuidades pero asimismo con rupturas.

- OROzCo Díaz, Emilio, Cervantes y la novela del Barroco, Universidad de Granada, 1992.

Reunión asimismo póstuma de los escritos cervantistas del autor, quien reflexiona sobre lo manierista y lo barroco del Quijote, y traza una bella y hasta emotiva glosa del Persiles. Volumen atractivo, con algunos esbozos también de sociología literaria.

- PÉRez, Luis C. y SÁNChez Escribano, Federico, Afirmaciones de Lope de Vega sobre preceptiva dramática, Madrid, CSIC, 1961.

Los autores se refieren a los planteamientos de Horacio, y analizan en cien comedias de Lope que han leído la versión que se da en ellas a los temas «natu- 
raleza y arte», «entretener-deleitar» y «pintura y poesía»; del mismo modo se refieren a la problemática aristotélica tal como aparece en el dramaturgo.

Trabajo enormemente documentado, lo tenemos por una aportación de relieve. Por nuestra parte esbozamos lo que debe atribuirse a Aristóteles y a Horacio en la tradición preceptiva en Caracterización de la literatura española, Madrid, UNED, 1983, pp. 13 ss.

- SÁINZ Rodríguez, Pedro, Historia de la Crítica literaria en España, Madrid, Taurus, 1989.

Obra póstuma e inacabada, pero que transmite la experiencia y el conocimiento por dentro que tenía el autor del pasado de nuestras letras.

- SÁnchez Escribano, Federico y PORQUERAs MAYo, Alberto, Preceptiva dramática española, Madrid, Gredos, 1972².

Repertorio insustituible de textos, con el complemento de varios estudios en uno de los cuales Porqueras advierte por ejemplo cómo «es Cascales el primero en Europa» en formular una clasificación de tres géneros: «lírica, épica y drama».

Estamos ante el trabajo de dos insistentes especialistas en historia de la teoría literaria.

- VILANova, Antonio, «Preceptistas españoles de los siglos XVI y XVII», en la Historia General de las Literaturas Hispánicas, Barcelona, Barna, III, 1953, pp. 565-692.

Exposición ordenada y completa - dentro de las limitaciones de espacio de una obra colectiva - de las doctrinas literarias españolas del Quinientos y el Seiscientos. Trabajo hecho con la rigurosidad erudita y la inteligencia y belleza expresiva que caracterizan al autor.

III

La lectura de los textos mencionados parece confirmar algunas inducciones:

1. La historia de la lengua y la historia de las ideas lingüísticas resultan en parte inseparables, como lo son asimismo la historia de la literatura 
y la de las ideas literarias. Estamos ante diacronías respectivamente secantes entre sí.

2. Quizá la época menos conocida por lo que respecta a las doctrinas lingüísticas y literarias sea el siglo XIX.

3. Tampoco la historia de la lengua y la de la literatura resultan separables. No se trata sólo de lo que tienen de común en cuanto historias del arte, sino de que la gramática del pasado no la conocemos en parte sino por los testimonios literarios.

4. «La filología española no ha conseguido mantener el nivel de calidad que tuvo en los treinta o cuarenta años iniciales de nuestro siglo... Continuamos nutriéndonos en gran medida de lo que se produjo en aquellas primeras décadas, alguna de cuyas investigaciones son todavía hoy inexcusables puntos de referencia» (Ricardo Senabre).

5. «La bibliografía es tarea de precisión, erizada de dificultades, y tal vez por eso despierta poco entusiasmo entre los jovenes investigadores, a los que convendría estimular» (R. Senabre). 